\title{
Cultural Development meets Rock and Roll (or what government can learn from pop music festivals)
}

\author{
International Journal of Cultural Policy, \\ 2001, 7, 3, 479-492.
}




\section{Abstract}

An interrogation of the dissonance between youth art policy and the actual forms of youth cultural production and participation is informative in relation to discussion of cultural development. These debates are characterised by discussion of the relations between culture and the construction of identity, cross-sectoral partnerships for sustainable cultural funding, and the convergence of cultural forms. Youth arts policy presents challenging opportunities to develop cultural policies which are grounded in new paradigms of support. Cultural development is being articulated as just such a new paradigm for cultural policy. This new paradigm involves the facilitation of cross-sectoral partnerships which support cultural process, practice and production and not, or at least not only, cultural things. The objective of this paradigm for cultural support is sustainable cultural development articulated around different policy objectives linked to specific local, national or global communities. Commercial music festivals are cultural programs which are unparalleled in their ability to attract the 'youth' cohort. Commercial music festivals present ideal opportunities for sustainable partnerships between for-profit and not-for-profit cultural organisations which facilitate the presentation of diverse cultural product. Until cultural policy comes to terms with the real diversity of cultural expression and participation it is not practicing 'cultural development' at all but remains primarily informed by a 'civilising' construction of the uses of art.

\section{Keywords}

Youth Arts Policy, Cultural Development, Cultural Diversity, Cultural Funding, Festivals 


\section{Introduction ${ }^{1}$}

Analysis of the history and organisation of the Livid Festival, an Australian popular music festival, is instructive in relation to international debates on 'cultural development'. This debate is characterised by discussion of the relations between culture and the construction of identity, cross-sectoral partnerships for cultural funding and the convergence of cultural forms. In youth cultural productions there are numerous examples of convergence between public and private cultural spheres, and cultural forms which are primarily subsidised or commercial. In popular music festivals, dance parties and nightclubs, avant-garde, heritage and commercially successful (or at least viable) cultural forms are presented and participated in, in ways which converge the traditional distinctions between these forms as well as the distinctions between audience and producer. In addition these programs provide frameworks for the convergence of commercial and subsidised cultural forms in ways which are specifically aimed at achieving large-scale audience participation. To support youth culture as youth engages in and creates it will require a significant broadening of the role of the traditional arts funding agency both in terms of the product and audiences it supports and the models of funding it develops.

Cultural policies targeted at youth present a challenging opportunity to develop cultural policy which is based on a new paradigm of cultural support. Above all this new paradigm for cultural support can be defined as involving the facilitation of cross-sectoral partnerships which support cultural process and not or at least not only cultural things. The objective of this paradigm for cultural support is sustainable cultural development

\footnotetext{
${ }^{1}$ Part of this paper was written for the First Joint Study Project on Culture and Development in the AsiaPacific Region organised by the Korean National Commission for UNESCO. The aims of this project were to
} 
articulated around different policy objectives linked to specific local, national or global communities. Recognising the potential of cultural programs such as popular music festivals, which routinely (not only as an exception) deal with convergent forms, practitioners, modes of participation and audiences, will aid us in thinking through the discursive reconstruction which is necessary if we are to develop cultural policy which is not characterised by a janus face of 'Profit' and 'Culture'.

\section{Cultural Development}

A number of international conferences and seminars in the last two years have discussed the changing nature of the non-profit arts sector. ${ }^{2}$ For non-profit arts organisations the major factors affecting this change have been summarised as the gradual withdrawal of government from direct funding of the cultural sector (as well as the welfare sector in general); globalisation of the cultural market and intensification of competition for audience attraction in local cultural markets; changing nature of audience constitution and practices; increasingly culturally diverse nature of national populations; and, identification of a new 'non-arts' revenue in the public sector as well as in previously untapped parts of the commercial sector (Lavigne 1998, pp. 13-15).

It is clear in those countries which have had the luxury of strong public sector support for the arts that maintaining the status quo is not possible nor desirable. Even in those countries where public support has not had a strong tradition, increased competition for the arts dollar

provide information which could be used in the formulation, evaluation and implementation of cultural policy in the region.

${ }^{2}$ See for instance François Colbert, ed. 1998, Cultural Organisations of the Future: Colloquium Proceedings, Montréal, Canada, École des Hautes Études Commerciales de Montréal; National Association of the Visual Arts, 1998, Art of Sight Art of Mind, http://www.culture.com.au/nava/sight.html; Privatization of Culture 
has meant that non-profit arts organisations have needed to be self-searching about what they see as being their role and how they access funding to facilitate this role. This has been particularly so in relation to the convergence of cultural practices and tastes, where the distinctions between what should and should not be funded are increasingly open to question. In addition to an interrogation of the kinds of projects funded by arts organisations there is an even more basic concern: 'how to fund the arts?' In response to these concerns cultural development is being articulated as the new model of arts support.

The primary focus of the cultural development agenda has been the application of notions of 'development' and 'sustainability' to the relations between communities and culture. Cultural development programs are based on the encouragement of partnerships between non-profit, government, business, and philanthropic agencies in order to encourage cultural sustainability (Intergovernmental Conference on Cultural Policies for Development 1998, pp. 13-19). However, while the logic underpinning UNESCO's cultural development statement Our Creative Diversity is democratic and pluralist we must bear in mind that cultural policy is inescapably normative, that is, cultural development policies cannot be neutral (de Cuéllar 1996). Tony Bennett and Colin Mercer make the point in a report commissioned for UNESCO that

'Culture' and 'development'... were first put together in the context of western programs of cultural assimilation... how 'culture' and 'development' are put together and the role that cultural policies play in meditating the connections between them are, ultimately, questions concerning the frameworks within which, at both the national and the international levels, the relationships between different human ways of living will be managed. (1998, p. 5)

Project, New York University, 1998, New Directions in Cultural Policy Conference, http://www.nyu.edu/projects/privculture/confer.htm. 
While cultural development sits comfortably within a socially democratic language, nevertheless, we must remain aware that the funding of culture involves a choice, which has political, social and economic ramifications, as to what is funded and what is not. The cultural products which youth produce and consume have not to date tended to be a focus of cultural funding, rather, the market has governed the cultural spheres in which youth participate. If our contemporary policy understanding of culture is as 'people's own way of life as a value, as a right, as a responsibility and as an opportunity' and not 'the frame of reference in which the West's system of values alone generated rules assumed to be universal' (de Cuéllar 1996, p.7), then it will be necessary to move away from our traditional narrow definition of 'the arts'. This will be as important for communities asserting their identities within national boundaries as it will be on the international stage.

\section{Cultural Consumption and Youth}

Ten years ago Paul Willis's paradigmatic study of youth Common Culture argued that most youths, while 'not involved with the arts', are 'all the time expressing or attempting to express something about their actual or potential cultural significance' (1990, p. 1). The Australian Cultural Consumption Project, an extensive study of Australian cultural tastes, preferences and activities, found that under-25-year-olds had a very high rate of participation in cultural activities with strong attendance rates at 'rock concerts, movies, theme parks, night clubs, pubs with live bands and film festivals' (Bennett, Emmison and Frow 1999, p. 250). In addition while young people 'read more Australian authors than other cohorts', music was found to be 'the cultural domain of greatest significance' (ibid.). These findings are supported by the Australian Bureau of Statistics (ABS) study of Youth and the Arts which found that youth had a very high rate of participation in a range of 
cultural activities. For instance, attendance at popular music concerts was at ate twice that for older people; in a range of occupations in the performing arts and film and video sectors there was a higher than average representation of youth; and, younger households spent $40 \%$ a week more on cinema admission and $70 \%$ more on music than average households (ABS 1996, pp. 2-3).

In the Australians and the Arts survey of Australian attitudes to 'the arts' Saatchi and Saatchi Australia described the profile of young people in the following way: compared with the overall population sample, young people 15 to 24 years are more likely to feel neutral about the arts or not like them. While they are more likely to have a limited spontaneous definition of the arts, they are also slightly more likely to accept the 'little a' arts and to accept slightly more items in a future definition of the arts. (2000, p. 217)

Saatchi and Saatchi's finding, in contrast to other surveys which document that young people participate more than average in a large range of cultural activities, registers that young people show a disinterest in 'the arts'. It is important to make clear at this point that the Australians and the Arts survey measured attitudes to the arts on the basis of the survey participant's definition of what constituted 'the arts'. Unsurprisingly $79 \%$ of those surveyed identified only four items or less which 'came to mind as part of “the arts"?' $(2000, \mathrm{p} .171)$. However, the survey also found that when young people were asked to expand that definition they provided a more extensive definition of 'the arts' than other segments of the population (2000, p. 217). Clearly what is at issue here is the distinction in the meaning of the two terms 'culture' and 'arts'. How then is youth arts policy to negotiate this problematic that the arts product it has traditionally supported is not the arts product that youth produce and participate in the most? Should audience development as it is targeted at youth continue to aim to encourage attendance and participation in cultural forms which 
youth have clearly demonstrated they are not interested in or is there a more basic question at stake here, one which requires us to interrogate what we are supporting, for whom and why? In order to address these questions we need to investigate the particular dimensions of youth cultural production and participation.

When cultural activity is measured account is taken of the sphere of commercial cultural production: television, popular music, computer games, dance parties, and so forth. When we discuss 'the arts' we are usually referring to the non-profit cultural sector. The Youth and the Arts study shows that 'the difference in the magnitude of the participation rates between youth and the older population' for venues usually defined as 'arts' venues 'was minimal' and indeed the proportion of youth attending theatre was significantly higher than other age groups (ABS 1996, p. 16). However, this study also found that 'the participation rate for full time students aged $15-24 \ldots$ is higher for all venues/ activities, except popular music concerts, than for young people not engaged in full time study' (ABS 1996, p. 17). Thus, our understanding of youth cultural consumption needs to be more sophisticated than one which imagines simply that young people consume commercial culture (popular music, computer games, and so forth) and not 'the arts'. Rather, levels of youth participation in the entire cultural field are linked to socio-economic factors and above all to educational capital.

French sociologist Pierre Bourdieu has argued that individual cultural consumption and participation is integrally connected to 'cultural capital' which is in turn linked to level of 
educational attainment. ${ }^{3}$ Bourdieu argues that in culture produced and distributed commercially by the mass media consumption 'is more or less independent of the educational level of consumers'; however, the fields of restricted culture (the 'high' arts) 'owe their... cultural rarity, and thus their function as elements of social distinction, to the rarity of the instruments with which they may be deciphered' (1993, p. 120). Tony Bennett summarises Bourdieu's identification of the contradictory social logic which characterises arts policy in the following way:

On the one hand, the publicness of these institutions - their reliance on public funding and administration, their openness to everyone-places them, at least in theory, in the realm of unrestricted culture. On the other hand, however, the forms of culture whose production and circulation is dependent on, and takes place through, these institutions belong to the realm of restricted culture in the sense that their consumption - that is, the capacity to access them intellectually and culturally-depends on the acquisition of particular cultural skills which, since these are selectively distributed via the education system are socially rare. (1997, p. 91)

What does this mean for cultural policy as it bears on youth? Does this mean that youth cultural policy should focus on providing access to those governmentally subsidised forms of culture which youth with lower levels of education have demonstrated limited participation in? Or does this mean that there is no role for youth cultural policy or the funding of 'youth arts' because evidence shows that the commercial market provides the cultural product that youth most consumes?

It is clear that the key issue for arts programs targeted at youth is the ability of the traditional arts funding structure to build sustainable and productive partnerships with commercial cultural organisations. Indeed, the facilitation of cross-sectoral partnerships for arts funding is a major focus of contemporary arts policy more generally. How can

\footnotetext{
${ }^{3}$ See especially the development of this argument in Distinction: A Social Critique of the Judgement of Taste
} 
government arts funding agencies and non-profit arts organisations build relations with commercial cultural organisations in ways which allow these agencies to retain their focus on the 'public interest' components of their missions?

\section{What Government can learn from Pop Music - the Livid Festival}

Commercial popular music festivals are cultural programs which are unparalleled in their ability to attract the 'youth' cohort. Commercial music festivals present an ideal opportunity for sustainable partnerships between for-profit and not-for-profit cultural organisations which would facilitate the presentation of diverse cultural product. The significance of music festivals is clear if we take into account the finding of Youth and Music in Australia that while 'participation rates for all categories [of music] were higher among those studying full-time' this was not the case for popular music where the participation rate was $43.3 \%$ for those studying full-time and $46.2 \%$ for those not studying full-time (London and Hearder 1997, p. 39). ${ }^{4}$ Thus, in keeping with Bourdieu's finding that participation in the commercial cultural field was independent of cultural capital, in Australia, participation in popular music attracts an audience which is not limited by educational attainment. Furthermore, 'the proportion of 15-24 year olds who went to popular music concerts (45.1\%) was...significantly greater than the percentage of people aged 25 years or more who attended popular music concerts (22.6\%)' (ABS 1996, p. 16). Indeed for the 15-17 year old age group outdoor music festivals were the most attended forms of musical event. If the aim of cultural policy is to facilitate democratic access to a range of cultural products and experiences, on these findings the popular music festival is an unmatched site for facilitating this access. However, if traditional arts organisations are to seek partnerships 
with alternative cultural providers it will require a shift in policy which will take account of the sites in which youth produce and participate in culture. Many of these sites are commercial. Willis argues that

our best chances of encouraging an artistic democracy are not through 'democratisation' of 'the arts'- opening access for new 'publics' to the established institutions and practice- but through an identification, recognition and support of existing creative experiences and activities not at present regarded as 'artistic' but which are now part of our common culture. (1990b, p. 10)

It is in this way that an interrogation of successful youth cultural programs such as the Livid Festival can be informative in relation not only to youth cultural policy but also to cultural policy as a whole.

Popular music festivals have a long history, Woodstock in America and Glastonbury in England immediately come to mind as classic pop music festivals. The Livid Festival, staged in Brisbane, Queensland, is Australia's longest running rock and roll festival having been established in 1988. Livid was started as a reaction to the International Exposition which was held in Brisbane in 1988. In the context of Expo ' 88 it was conceived as an oppositional forum for the exhibition of Brisbane art and music produced by young people. Despite its massive growth and commercial success Livid still retains this focus on providing a space for the display of young Brisbane artists and musicians. The Festival operates on a philosophy of acting as a forum for young local artists. The first Livid was held under a circus 'Big Top' tent and involved two stages alternately showing bands and performance art. As the Festival became bigger the focus on the art component was reduced, by 1990-91 the performance stage had taken a minor role. According to Peter Walsh, founder of the Festival and one of its current Directors, the removal of the

\footnotetext{
${ }^{4}$ See also Australian Bureau of Statistics 1996, p.17.
} 
performance stage from major stage status was as a result of a change in the Festival's audience demographic. According to Walsh the audience for music over the past eleven years has become younger. This observation is in accord with a number of significant changes in radio programming over the last ten years.

The demise of Australian teen radio during the 1980s is well documented. According to Graeme Turner 'since the introduction of commercial FM radio in 1980, and increasingly ... since the upheavals in media ownership in 1986-7, teen radio has disappeared from metropolitan Australian radio' (1993, p. 143). However, in contrast to the general trend, since the early 1990s the Australian Broadcasting Corporation's (ABC) national youth radio station Triple $\mathrm{J}$ has been strengthening its appeal particularly amongst the 10-17 year old radio listening market (Cupitt, Ramsay, and Sheldon 1996, p. 25). In 1990-91 Triple J underwent a change of policy in relation to its programming format. Specifically this policy change was to shift its target audience to 15-24 year olds, a move down the demographic ladder. This move was received with a great deal of concern as it was perceived as commercialisation and therefore against the charter of the station (Creswell 1991, p. 27). Triple $\mathrm{J}$ is a national radio network whose format is to present 'new and emerging music', which consists of a mix of new Australian music and music from overseas (Cupitt, Ramsay, and Sheldon 1996, p. 25). It is this focus on new and Australian music which was seen to be threatened by targeting a younger audience. This is understandable in view of the under-25 audience's preference for American music over Australian music (Bennett, Frow, Emmison 1999, p. 249). On the other hand, Triple J argued that this adjustment in policy focus meant that the station was providing a more democratically accessible service in a station which was previously seen to cater only to an educated middle class urban elite. The new strategy, 
which included a focus on regional youth audiences, 'acknowledges the disenfranchisement of a large section of the radio audience and attempts to do something about it' (Turner 1993, p. 153). While we cannot prove the links between the broadening of the audience for 'alternative' music, particularly as this has been supported by Triple J, and the demographic shift noted by Walsh in the Livid Festival audience the fact remains that the audience for Livid has grown at a great rate since the early 1990s. Indeed despite the fact that a plethora of other festivals have emerged in recent years to compete for the substantial commercial value of Livid's audience, the Festival has continued to grow from 1800 ticket sales in 1988 to 2000 's 40,000 ticket sales. $^{5}$

The art program at Livid plays a significant role in providing a point of focus which acts as a link between fundamentally different audiences in a situation which could be potentially antagonistic. While it is undeniable that the main audience attraction at Livid is the music, the art program contributes to the construction of the festival as more than simply a big commercial event. Livid is the only commercial youth music festival in Australia which has an art program. The art program and local bands position Livid as a specifically Brisbane show. This is not to say that the Livid Festival only consists of 'homegrown' music and art but that there is a significant effort made to ensure that a component of the music program (in 1999 twelve bands out of fifty) and the emphasis of the art program provides a venue for emerging Brisbane artists.

The art at Livid is also iconographic of each year's festival. For instance, in 1994 and 1995 Brisbane artist Craig Walsh installed a series of monumental heads. Peter Walsh argues that

\footnotetext{
${ }^{5}$ The Livid Festival is second in size only to the Big Day Out which is a touring outdoor rock and roll festival.
} 
it is these heads which most people recall from those Festivals and not the headlining band. At Livid 1999 an appearance was made by Pope Alice (alias Brisbane performance artist Luke Roberts) who in an ironic reflection on religion and the end of the millennium moved through the 35,000 crowd encased in his Popemobile dispensing religious relics.

Despite the engagement of the audience and the success of the art program component of Livid there has been no successful attempt to facilitate partnerships between not-for-profit or government arts organisations and Livid. ${ }^{6}$ Currently Livid self-funds the art program out of the profits generated by the Festival. This has been primarily due to the difficulty of negotiation between the commercial interests of the Festival and the traditionally based policy logics which frame most grant programs. Retention of this program as part of the Festival has required constant lobbying. This lobbying has come not so much from the 'arts community', as traditionally defined, but from those practitioners and audiences who produce and engage with the convergent cultural forms which characterise cultural activity in festivals like Livid.

The Livid Festival plays an important role in the development and maintenance of the local cultural industry. In addition to the musicians and artists who take part in the Festival there is an extended network of small cultural businesses including, promoters, tour managers, graphic designers, publicists, and multi-media companies which, in part, have developed as a result of and owe their sustainability to the ongoing commercial success of Livid. Many of these micro cultural businesses also work in the local subsidised art sector. Thus, there is cross subsidisation between the commercial and subsidised sectors which means that Livid 
has a significant effect on both the local commercial and subsidised cultural infrastructures. Yet in the locality out of which Livid operates, the market still governs support for emergent cultural businesses. As a result of this there are serious inequities in the ability of people to access the resources necessary to establish, or at least to attempt to establish, a cultural business which might be competitive in this environment.

\section{Conclusion: Cultural Policy and Youth}

In the last decade in Australia there have been a number of attempts to develop policy which addresses youth arts practice and youth arts audiences. Up until recently youth arts policy has tended to be articulated in the language of disadvantage-youth need help accessing 'the arts'; in the language of welfare - access to the arts will help disaffected youth; in relation to training new artists; and, in relation to building a new audience for the arts. Thus, while there have been many attempts to recognise the diversity of young people's involvement in culture, as Mary-Ann Hunter argues there 'nevertheless remains a systematic bias in measuring and supporting [the cultural] industry which devalues youthspecific ... modes of production' (1999, p. 123). Instead youth arts policy has tended to position youth in relation to a narrowly defined conception of 'the arts'. Jennifer Craik has characterised the resulting tensions as involving 'the difficulty of reconciling youth culture as broadly practised and consumed with youth culture that is the object of policy initiatives' (1998, p. 3).

The Australia Council, the Commonwealth Government's arts funding body, launched its Youth and the Arts Framework in October 1999. This attempts to provide a conceptual

\footnotetext{
${ }^{6}$ That is apart from a small grant from the Brisbane City Council in 1996 to fund aspects of the art program.
} 
framework for 1999-2001 within which the Council can develop policy which takes account of youth. The framework begins with a broad definition of culture as including 'cultural activities [which] reflect people's thoughts and experiences of life and do not simply consist of literature, music, performing arts, visual arts, cinema and photography' (1999, p. 16). The framework also understands 'what young people do, own and value, [as] not an extraneous or marginal element of Australian life. Young people are energetic and imaginative participants in and contributors to Australian culture and bring to it a perspective which can be different from any other group' (1999, p. 17). However, the framework used the findings of the Australians and the Arts survey when it contextualised itself by stating that 'young people often report seeing the arts as too expensive, inaccessible and often just uninteresting' (1999, p. 20). As already mentioned the Australians and the Arts survey measured attitudes to the arts on the basis of the survey participant's definition of what constituted 'the arts', 79\% of respondents identified four items or less as constituting 'the arts'. In this context the Youth and the Arts Framework urged 'all artists and arts organisations to consider how young people can have access to their work, what information is available about the art made and presented, what prices are charged and when and where the art is available' (1999, p. 20). This reflects the disjunction between the cultural processes which youth produce and consume and the arts products which arts organisations have traditionally supported.

The Youth and the Arts Framework is an exciting opportunity for the Australia Council to reposition its programs and policy aims in a way which would bring it in line with the 'new paradigm' of cultural policy as it is being articulated internationally and as it has been taken 
up in various ways by some State and local governments. ${ }^{7}$ While it is too early to tell what impact the Youth and the Arts Framework will have, it seems clear that it is not advocating any radical departure from the Australia Council's role supporting 'traditional youth arts'.

I have discussed above the ways in which the cultural development agenda advocates supporting culture where, when and as it is created by communities and funding it from within these communities. The Livid Festival is a cultural program which is informed by a plural engagement with the cultural forms which young people produce and consume. There is much to be learnt from applying the challenges to policy presented by engaging with the actual cultural forms which youth produce and consume. Colin Mercer and Gillian Swanson in arguing that youth arts policy must be situated within a general framework of strategic cultural development recommend that 'mechanisms of liaison, policy coordination and partnership between the Australia Council and other agencies in the public and private sectors are a precondition of effective policy development and implementation' (1990/91, p. 169). In other words arts funding agencies will need to define their objects broadly and recognise that youth arts policies must start from where young people are. As Bennett et al point 'it is clear where they are not: they are not in the art gallery, the artcinema, theatre, opera or concert hall. Nor should it be assumed that this is a failing on their part or that the only valid purpose of youth-arts subvention is to attract young people to these cultural sites' (Bennett et al 1990/91, p. 153). Youth participate in a broad range of cultural practices many of which occur in the commercial sphere. It is here that there is a clear role for government arts funding in starting from where youth culture is and playing a

\footnotetext{
7 See for instance the Queensland State Government's Cultural Policy for Young People (2000) which supports A-Venue, a scheme which facilitates access for young people to the music industry (http://www.avenue.org/info.htm) and YAMP, a youth arts mentoring scheme (http://home.pacific.net.au/ yamp/\#).
} 
role by 'intervening in the operation of current market arrangements' (Bennett et al 1990/91, p. 152). This would be particularly in order to ensure that despite the increasing privatisation of culture there are mechanisms which protect public interest policy objectives. In this case one could see a role for a government arts project in acting in a partnership with Livid in order to fund components of the art and music program to ensure, for instance, that there are opportunities at Livid for local early career artists to take advantage of Livid as one of Australia's largest annual gatherings of young people for the purposes of a cultural festival. It is from initiatives of this kind that youth arts policy should take its bearings. 


\section{Bibliography}

Australia Council 1999, Youth and the Arts Framework, Australian Council, Sydney.

Australian Bureau of Statistics 1996, Youth and the Arts, Cultural Industries Statistics Working Group, Cultural Minister's Council.

Bennett, T. 1997, 'Consuming culture, measuring access and audience development', Culture and Policy, 8, 1, pp. 89-113.

Bennett, T., Emmison, M. and Frow, J. 1999, Accounting for Tastes: Australian Everyday Cultures, Cambridge University Press, UK.

Bennett, T., Miller, T., Swanson, G. and Tait, G. 1990/91, 'Youth Cultures and Arts Policies', Culture and Policy, 2 \& 3, 2 \& 1, pp. 135-156.

Bennett, Tony and Mercer, Colin 1998, Improving Research and International Cooperation for Cultural Policy, UNESCO.

Bourdieu, P. 1993, The Field of Cultural Production: Essays on Art and Literature, Polity Press, Cambridge.

Bourdieu, P. 1994 Distinction: A Social Critique of the Judgement of Taste, Routledge and Kegan Paul, London.

Colbert, François, ed. 1998, Cultural Organisations of the Future, Montréal, Canada, École des Hautes Études Commerciales de Montréal.

Craik, J. 1998, 'Does Youth Arts Policy Make a Difference?', Paper for the Youth Cultural Debate Session of ARTEX National, unpublished.

Creswell, T. 1991, 'Radio Daze', Rolling Stone, 450, pp. 27-29.

Cupitt, M., Ramsay, G. and Sheldon, L. 1996, Music, New Music and All That: Teenage Radio in the 1990s, Australian Broadcasting Authority, Sydney.

de Cuéllar, J.P. 1996 Our Creative Diversity: Report of the World Commission on Culture and Development, UNESCO.

Hunter, Mary-Ann 1999, 'Redefining Industry: Young People and Cultural Policy in Australia', Media International Australia incorporating Culture and Policy, 90, pp. 123138.

Intergovernmental Conference on Cultural Policies for Development 1998, Final Report, UNESCO. 
Lavigne, M. 1998, 'Welcoming Address', Cultural Organisations of the Future, Colbert, F., ed. Montréal, Canada, École des Hautes Études Commerciales de Montréal.

London, J. and Hearder, J. 1997, Youth and Music in Australia-a review, Australian Broadcasting Authority, NSW.

Mercer, C. and Swanson, G. 1990/91, 'Reviewing Youth Arts: Policy Implications', Culture and Policy, 2 \& 3, 2 \& 1, pp. 157- 172.

National Association of the Visual Arts 1998, Art of Sight Art of Mind, http://www.culture.com.au/nava/sight.html.

Privatization of Culture Project 1998, New Directions in Cultural Policy Conference, http://www.nyu.edu/projects/privculture/confer.htm.

Saatchi and Saatchi 2000, Australians and the Arts: What do the arts mean to Australians, Australia Council, Sydney.

Turner, G. 1993, 'Who killed the radio star? The death of teen radio in Australia', Bennett, T., Frith, S., Grossberg, L., Shephard, J. and Turner, G., Rock and Popular Music: Politics, Policies, Institutions, Routledge, London.

Willis, Paul 1990, Common Culture; Symbolic work at play in the everyday cultures of the young, Open University Press, Milton Keynes.

Willis, P. 1990b, Moving Culture: An inquiry into the cultural activities of young people, Calouste Gulbenkian Foundation, London. 